\title{
Anthropometric status of complicated severe acute malnutrition children at a tertiary care hospital in Southern Rajasthan, India
}

\author{
Meena $^{1}$ S.K., Vivek Parasher ${ }^{2}$ \\ ${ }^{1}$ Dr. Suresh Kumar Meena, Assistant Professor, ${ }^{2}$ Dr. Vivek Parasher; Associate Professor, both authors are affiliated with the \\ Department of Pediatrics, Pacific Institute of Medical Sciences, Udaipur, Rajasthan, India
}

Correspondence Author: Dr. Suresh Kumar Meena, Department of Pediatrics, Assistant Professor, Pacific Institute of Medical Sciences, Udaipur, India. E-mail: sureshmeenaspmc@gmail.com

\begin{abstract}
Introduction: Severe acute malnutrition (SAM) is major health problem in our country. In complicated SAM there is high morbidity and mortality, so they require hospitalization for facility based management. Aims and Objectives: To study the anthropometric severity of complicated SAM. Material and Method: This was retrospective study to evaluate anthropometric severity in children admitted in last 6 months between Februarys to august 2019, at our tertiary care hospital PIMS Umarda Medical college, Udaipur, Rajasthan. As per our MTC protocol all children $<5$ years were assessed clinically \& anthropometrically by a trained resident doctor in facility based management of SAM. These anthropometric data were calculated by using WHO Anthropometric calculator \& entered in datasheet regularly and then these data were analyzed. Result: Out of 100 complicated SAM children, majority of population $76 \%$ were in the age group of 6 months to 2 years. As per various criteria of SAM, majority of them $73.0 \%$ children were in SAM as per WFH/L criteria, $52.0 \%$ children fulfilled MUAC criteria and $14.0 \%$ of children were edematous. Majority of study population was under $<-3$ SD and $<-4$ SD z-Score $(53.0 \%)$ followed by $<-5 \mathrm{SD}$ z score $(23.0 \%)$ and $9.0 \%, 6.0 \% \& 1.0 \%$ study children were in $<-6 \mathrm{SD},<-7 \mathrm{SD} \&<-8 \mathrm{SD} \mathrm{z}-$ score respectively as per WHO reference charts. In the present study population of SAM children mean weight was $6.021 \pm 1.39 \mathrm{~kg} \&$ average height was $70.29 \pm 7.58 \mathrm{~cm}$. Mean MUAC was $10.95 \pm 1.19 \mathrm{~cm}$. Mean Head circumference and BMI were $42.16 \pm 2.25 \mathrm{~cm}$ and $12.20 \pm 2.44 \mathrm{~kg} / \mathrm{m}^{2}$ respectively. Conclusion: To conclude, our hospitalized SAM patients had very marked severity of anthropometric indices, which indicate not only SAM but also chronic malnutrition. So it was recommend from this study, community management should be strengthened for management and prevention of malnutrition.
\end{abstract}

Keywords: Anthropometric, Co-morbidities, Severe acute malnutrition, Z-score

\section{Introduction}

Severe acute malnutrition (SAM) is one of the most common health problems involving hundreds of millions of children in the world [1]. According to National Family Health Survey-4, in India 7.5\% of children below 60 months of age suffer from SAM and this has increased from the previous value of $6.4 \%$ children in NFHS-3 [2].

Programmatically, it is helpful to categories children with SAM into complicated and uncomplicated. However, in children with severe acute malnutrition, addressing the problem through facility based approach alone is unfeasible. In children, undernutrition is synonymous with growth failure - undernourished children are shorter and lighter than they should be for their age/height. To get a measure of malnutrition in a population, young children are weighed and/or their height is measured and the results

Manuscript received: $14^{\text {th }}$ October 2019

Reviewed: $24^{\text {th }}$ October 2019

Author Corrected: $30^{\text {th }}$ October 2019

Accepted for Publication: $4^{\text {th }}$ November 2019 compared to those of a 'reference population' known to have grown well. Measuring weight and height is the most common way of assessing malnutrition in a given population. Such use of measurements of dimensions of the human body is known as anthropometry.

Anthropometry is a widely used, inexpensive and noninvasive measure of the general nutritional status of an individual or a population group. The three commonly used anthropometric indices are: Weight-For-Age (WFA).

Length-For-Age or Height-For-Age (HFA). Weight-Forlength or Weight-For-Height (WFH). Children suffering from undernutrition begin their lives with a significant disadvantage. As mentioned above, child malnutrition significantly contributes to under-five mortality as undernourished children have increased susceptibility to infections and hence frequent episodes of illness and longer recovery period [3]. 


\section{Original Research Article}

Besides increasing risk of mortality, undernutrition leads to growth retardation and impaired psychosocial and cognitive development. This further impact on education attainment.

The degree of cognitive impairment is directly related to the severity of stunting and iron Deficiency Anemia.

Without treatment, children who are affected by moderate or severe acute malnutrition during the critical stage of life between conception and age 2 , if not provided with timely and quality care, will find it difficult to achieve their full potential [4].

Hence this study aims to find out the anthropometric status in complicated malnourished children with different clinical conditions.

This would help to avoid life threatening situation by early recognition and proper therapy for growth failure in SAM children.

\section{Methods}

Setting-This was a hospital based prospective and casecontrol study.

Sample size- Sample size is calculated for unmatched case control study by using EPi info 6 software on the basis of previous study.

Study was conducted on 100 complicated SAM children aged 6-59 months and 50 children of uncomplicated SAM as control group.

Duration- Over a period of 6 months between February to august 2019, admitted in tertiary care hospital attached to medical college.
The study was approved by the ethical committee of the institute.

Inclusion criteria- A written informed consent was taken from parents of all malnourished children who fulfilled the inclusion criteria as per WHO reference of SAM in children of 6 months to 5 years.

- Weight for height/length $\leq 3 \mathrm{SD}$.

- Mid upper arm circumference (MUAC) of $<11.5 \mathrm{~cm}$.

- Bipedal nutritional edema.

\section{Exclusion criteria}

- Aged below 6 months and above 5 years.

- Refusal for consent.

All the enrolled children underwent a detailed clinical examination, including anthropometry (weight, length/ height, mid upper arm circumference, body mass index (BMI) and body surface area (BSA). routine investigations $(\mathrm{CBC}$, urea and creatinine, total serum protein, serum albumin SGOT, SGPT, blood sugar, HIV) were also done in all patients.

Statistical analysis: Results are expressed as mean \pm standard deviation for continuous variables and as number (\%) for categorical data.

Since all data were normally distributed, the parametric tests were used for statistical analysis. Pearson's correlation analysis was used to determine correlations between different variables.

For all tests, the difference was considered significant if the probability $(\mathrm{P})$ was $<0.05$. Statistical analysis was done by using SSSP version 20 .

\section{Results}

Out of 100 complicated SAM children, majority of population $76 \%$ were in the age group of 6 months to 2 years.

Mean age of complicated SAM was $16.45 \pm 10.40$ months \& consisted of $53.0 \%$ of males and $47.0 \%$ were of females and their sex ratio, M: F was 1.12 .

As per various criteria of SAM, majority of them $73.0 \%$ children were in SAM as per WFH/L criteria, $52.0 \%$ children fulfilled MUAC criteria and $14.0 \%$ of children were edematous shown Table 1.

In the present study population of SAM children mean weight was $6.021 \pm 1.39 \mathrm{~kg} \&$ average height was $70.29 \pm 7.58 \mathrm{~cm}$. Mean MUAC was $10.95 \pm 1.19 \mathrm{~cm}$.

Mean Head circumference and BMI were $42.16 \pm 2.25 \mathrm{~cm}$ and $12.20 \pm 2.44 \mathrm{~kg} / \mathrm{m}^{2}$ respectively. $\mathrm{P}$ value $=<0.001$ represented in Table 2. 
Original Research Article

Table-1: Distribution of study population on basis of SAM criteria.

\begin{tabular}{|c|c|c|c|c|c|c|c|c|}
\hline & \multirow{2}{*}{$\begin{array}{c}\text { Age } \\
\text { (Months) }\end{array}$} & \multirow{2}{*}{$\begin{array}{c}\text { WFH/L } \\
<-3 S D\end{array}$} & \multirow{2}{*}{$\begin{array}{c}\text { MUAC } \\
<11.5\end{array}$} & \multicolumn{5}{|c|}{ Edema } \\
\hline & & & & nil & $1+$ & $2+$ & $3+$ & Total \\
\hline \multirow{4}{*}{$\begin{array}{l}\text { Study } \\
\text { group }\end{array}$} & $6-<12$ & 32 & 21 & 35 & 3 & 0 & 0 & 38 \\
\hline & $12-<24$ & 29 & 26 & 40 & 5 & 3 & 0 & 48 \\
\hline & $>24$ & 12 & 5 & 11 & 1 & 2 & 0 & 14 \\
\hline & Total & 73 & 52 & 86 & 9 & 5 & $\mathbf{0}$ & 100 \\
\hline \multirow{4}{*}{$\begin{array}{l}\text { Control } \\
\text { group }\end{array}$} & $6-<12$ & 10 & 9 & 9 & 0 & 0 & 0 & 9 \\
\hline & $12-<24$ & 22 & 13 & 30 & 0 & 0 & 0 & 30 \\
\hline & $>24$ & 5 & 5 & 11 & 0 & 0 & 0 & 11 \\
\hline & Total & 37 & 27 & 50 & $\mathbf{0}$ & $\mathbf{0}$ & $\mathbf{0}$ & 50 \\
\hline
\end{tabular}

Table-2: Basic Anthropometric variables in SAM patients in study.

\begin{tabular}{|c|c|c|c|c|c|c|}
\hline \multirow{2}{*}{ Values } & \multicolumn{2}{|c|}{ Study group } & Control group & \multicolumn{2}{c|}{ Total } \\
\cline { 2 - 7 } & Mean & SD & Mean & SD & Mean & SD \\
\hline Weight $(\mathrm{kg})$ & 5.77 & 1.24 & 6.53 & 1.54 & 6.02 & 1.39 \\
\hline Height $(\mathrm{cm})$ & 69.55 & 6.88 & 71.77 & 8.71 & 70.29 & 7.58 \\
\hline MUAC $(\mathrm{cm})$ & 10.76 & 1.24 & 11.32 & 1 & 10.95 & 1.19 \\
\hline BMI $\left(\mathrm{kg} / \mathrm{m}^{2}\right)$ & 11.89 & 1.61 & 12.82 & 3.5 & 12.2 & 2.44 \\
\hline Head Circumference $(\mathrm{cm})$ & 41.98 & 2.37 & 42.54 & 1.97 & 42.16 & 2.25 \\
\hline
\end{tabular}

Majority of study population was under $<-3$ and $<-4$ SD z-score $(53.0 \%)$ while in control group (60.0\%) followed by <-5 SD z score in study group (23.0\%) in control group (18.0\%) and 9.0\%, 6.0\% \& $1.0 \%$ study children were in $<-6$ SD,$<-7$ SD \& $<-$ $8 \mathrm{SD}$ z-score respectively as per WHO reference charts. There were no children in control group of $<-7 \mathrm{SD} \&<-8 \mathrm{SD} \mathrm{z}$-Score. Shown in Table 3.

Table-3: Distribution of study population according to weight for length/height (WHO SD Z Score) reference chart.

\begin{tabular}{|c|c|c|c|c|}
\hline \multirow{2}{*}{ SD Z- Score } & \multicolumn{2}{|c|}{ Study group } & \multicolumn{2}{c|}{ Control group } \\
\cline { 2 - 5 } & No. of children & $\%$ & No. of children & 16.00 \\
\hline $\begin{array}{c}\text { Mean to } \\
<-2 S D\end{array}$ & 8 & 8.00 & 8 & 32.00 \\
\hline$<-3 S D$ & 26 & 26.00 & 16 & 28.00 \\
\hline$<-4 S D$ & 27 & 27.00 & 14 & 18.00 \\
\hline$<-5 S D$ & 23 & 23.00 & 9 & 6.00 \\
\hline$<-6 S D$ & 9 & 9.00 & 3 & 0.00 \\
\hline$<-7 S D$ & 6 & 6.00 & 0 & 0.00 \\
\hline$<-8 S D$ & 1 & 1.00 & 0 & $\mathbf{1 0 0 . 0 0}$ \\
\hline Total & $\mathbf{1 0 0}$ & $\mathbf{1 0 0 . 0 0}$ & $\mathbf{5 0}$ & \\
\hline
\end{tabular}


Original Research Article

\section{Discussion}

In the present study majority mean age of study population was $16.45 \pm 10.40$ months while in control population was $18.70 \pm 10.82$ months. Majority of population $(76 \%)$ of study \& $(70.0 \%)$ of control children were in the age group of 6 months to 2 years.

This finding is similar to results found in a study done by Gangaraj S. et al, (in 2008-2009), in Kamla Raja Hospital in India, with majority of severely malnourished children being 6-12 months (30.26\%) and 13-24months (32.8\%) [5].

In the present study, majority (53\%) of the study population were males and $47 \%$ were females. This can be explained by differential health seeking behavior of parents or this can be a normal representation of geographic population. Despite many public awareness programs male child is still preferred in India.

Study conducted by Aydin Ece et al [6]. had enrolled 74 malnourished children of which majority of them were males $(56.75 \%)$ and the mean age in months was $29.6 \pm 14.0$.

The study population was divided into groups based on weight for height/ length SD z core as per WHO anthro-calculator, it was observed that the majority of study population was under $<-3$ and $<-4$ SD z-score (53.0\%) while in control group (60.0\%) followed by $<-5 \mathrm{SD} z$ score in study group (23.0\%) in control group (18.0\%) and $9.0 \%, 6.0 \%$ \& $1.0 \%$ study children were in $<-6 \mathrm{SD},<-7 \mathrm{SD} \&<-8 \mathrm{SD}$ z-score respectively as per WHO reference charts. There were no children in control group of $<-$ 7SD \&<-8SD z-score.

Majority of study population was in <-3 SD z score and <-4 SD z score (63.0\%) although extremes like <-5 SD, <-6 SD and $<-7 \mathrm{SD}$ z score was also noted in $35 \%$ of population (as shown in Fig 1).

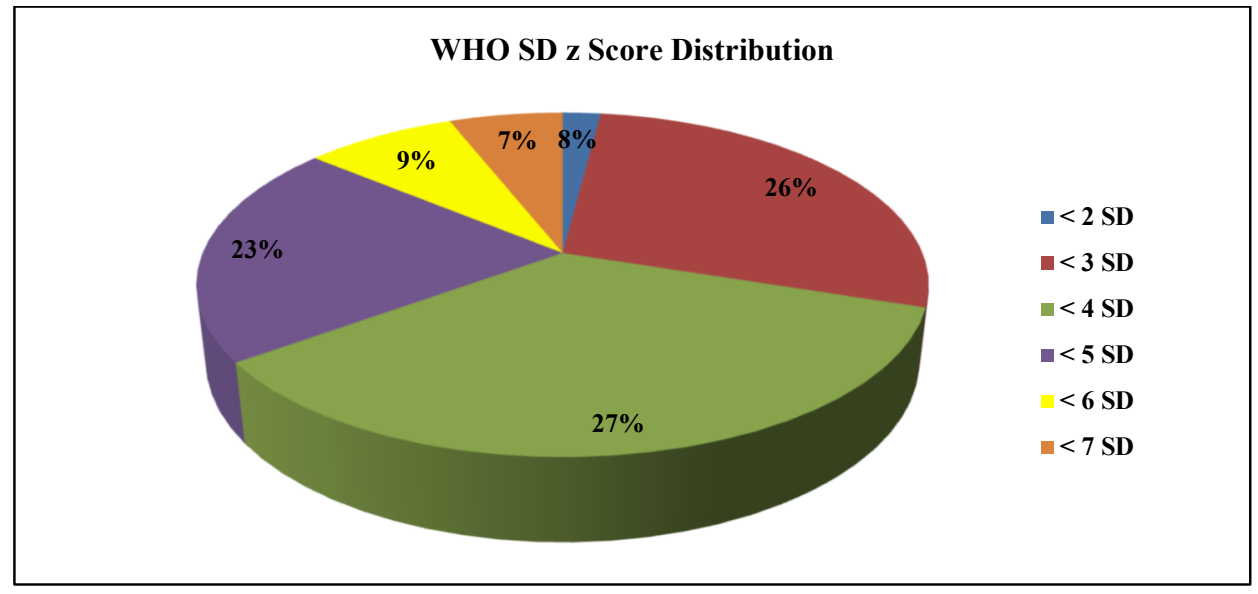

Fig-1: Distribution of study group according to

Weight for length/height (WHO SD z score) reference chart.

This signifies that severe form of malnutrition is still rampant in our society and efforts are needed to be made at large scale and more efficient ways to handle this social and health problem.

Various studies have been done on malnourished children but in most of them children were classified either as wasted or stunted or as Grade 1 - IV malnutrition as per IAP classification.

In present study, it was observed that the incidence of malnutrition was very high in mainly between $<-3 \mathrm{SD}$ to $<-4 \mathrm{SD}$ WHO z score.

Multicounty study conducted by Grellety and Golden [7] (2016) showed, in India, proportion of total children diagnosed as SAM with WHZ (84.5\%) were significantly high as compared to MUAC criterion (38.4\%) shows that, in each survey area, around $34 \%$ of children were from the age group of 6-23 months, and hence there was a possibility that more children would be identified by WHZ than MUAC. 
Original Research Article

If MUAC is used as a standalone criterion, then one-third of SAM cases of total caseload will get detected, implying that $70 \%$ SAM cases with $\mathrm{WHZ}<3 \mathrm{SD}$ will remain undetected at community level screening drive. However, global evidence suggests that MUAC identifies children who are at a higher risk of mortality and require immediate care [8]. Berkley et al. also suggested that MUAC is proven to be more sensitive than WHZ in identifying high-risk SAM children and predicting mortality [9]. Further analysis highlights that the proportion of SAM children detected with MUAC varied considerably across states. Of the total children with SAM, cases identified using MUAC in Attappady, Khutpani, Nabarangpur, Koraput, and Naraini were $12.5 \%, 32.2 \%, 25.6 \%, 22.2 \%$, and $46.1 \%$ compared to WHZ $100 \%, 93.6 \%, 94.9 \%, 94.4 \%$, and $96.2 \%$ respectively.

No significant differences in the proportion of GAM and SAM cases from different gender or different age groups were found when WHZ was used as an identification criterion. However, the analysis found that MUAC identifies slightly higher proportion of children who were young and females. This was also pointed out by other studies [10].

In Indian context, WHZ and MUAC criteria pick different sets of children as GAM and SAM. Around 25\% of GAM and SAM cases were identified by both the criteria. The current analysis tried to present a comparison between WHZ and MUAC criteria for the identification of children with acute malnutrition in a community setting, primarily to inform the policymakers and program implementers toward agreement and difference in case identification. Kappa coefficient shows a fair agreement between WHZ and MUAC for diagnosing acute malnutrition. The policy decision to use WHZ and/or MUAC as criteria for the identification of acute malnutrition depends on the objective of the program and resources. If the objective is to identify all the cases with acute malnutrition, then both criteria can be used together; however, if the program objective is to manage the children at higher mortality risk, then MUAC should be used. Using MUAC would decrease the caseload by about $68 \%$ that requires urgent management of SAM.

Limitation- A potential limitation of this study was that the analysis was based on data collected from children admitted to the OTP by MUAC criteria. However, because there was no significant difference in terms of their background characteristics in the proportion of children with low WHZ between the population and the study sample, our estimation of the gains in anthropometric measures is likely to reflect a valid estimate of the response in the children treated for SAM.

\section{Conclusion}

To conclude, our hospitalized SAM patients had very marked severity of anthropometric indices, which indicate not only SAM but also chronic malnutrition. So it was recommend from this study, community management should be strengthened for management and prevention of malnutrition. This study provides empirical evidence that supports the recent recommendation to use the same anthropometric indicator to identify children for the treatment of SAM and to monitor their response to nutritional rehabilitation programs.

\section{What the study adds to the existing knowledge?}

Udaipur is tribal part of Rajasthan where malnutrition is rampant. Many patients of severe acute malnutrition with all grades of SD z score that may be reaching up to 6 and 7 as per WHO SD z score classification. Our center is divisional as well as district head quarter having established malnutrition treatment Centre (MTC) since last 5 years. Malnutrition is a major cause of morbidity and mortality in SAM children. Previous studies conducted in malnourished children correlates growth retardation to various clinical conditions in SAM children. Studies are lacking to show the correlation between the grades of severity of malnutrition. Hence this study aims at exploring this area and also finds out the incidence of anthropometric severity (who $\mathrm{Z}$ scores) in malnourished children with different clinical conditions. This would help to avoid life threatening situation by early recognition \& proper therapy for catch-up growth in SAM children.

\section{Author's contributions}

Dr. Suresh Kumar Meena: Performed the clinical assessments, data collection and analysis of statistical work for this manuscript.

Dr. Vivek Parasher: Searched the literature and treated the patient until discharge and in drafted the manuscript. Both authors read and approved the final manuscript.

Funding: No funding sources

Conflict of interest: None

Ethical approval: The study was approved by the Institutional Ethics Committee

\section{Reference}

1. Sachdev HP, Kapil U, Vir S. Consensus statement: National Consensus workshop on management of SAM children through medical nutrition therapy. Indian Pediatr. 2010;47(8):661-665. 
Original Research Article

2. International Institute for population sciences. National family health survey 4. Mumbai India: International Institute of Population Science. 2016.

3. Facility based care of severe acute malnutrition. Ministry of Health and Family Welfare. Government of India. 2013:25-40.

4. Operational guidelines on Facility Based Management of Children with SAM. Ministry of Health and Family Welfare, Govt. of India. 2011; pp 4.

5. Gangaraj S, Das G, Madhulata S. Electrolytes and blood sugar changes in severely acute malnourished children and its association with diarrhoea and vomiting. Int J Pharm Sci Invent. 2013;2(5):33-36.

6. Ece A, Gözü A, Bükte Y, Tutanç M, Kocamaz H. The effect of malnutrition on kidney size in children. Pediatr Nephrol. 2007;22(6):857-863. Epub 2006 Oct 20. doi: 10.1007/s00467-006-0338-5.

7. Grellety E, Golden MH. Weight-for-height and midupper-arm circumference should be used independently to diagnose acute malnutrition: policy implications. BMC
Nutrition. 2016;2(1):10. https://doi.org/10. 1186/ s40795016-0049-7.

8. Briend A, Alvarez JL, Avril N, Bahwere P, Bailey J, Berkley JA, et al. Low mid-upper arm circumference identifies children with a high risk of death who should be the priority target for treatment. BMC nutrition. 2016;2(1):63. doi: https://doi.org/10.1186/s40795-0160101-7.

9. Berkley J, Mwangi I, Griffiths K, Ahmed I, Mithwani S, English M, et al. Assessment of severe malnutrition among hospitalized children in rural Kenya: comparison of weight for height and mid upper arm circumference. JAMA. 2005;294(5):591-597. doi: 10.1001/jama. 294. 5.591.

10. Grellety E, Krause LK, Shams Eldin M, Porten K, Isanaka $\mathrm{S}$. Comparison of weight-for-height and midupper arm circumference (MUAC) in a therapeutic feeding programme in South Sudan: is MUAC alone a sufficient criterion for admission of children at high risk of mortality? Public Health Nutr. 2015;18(14):2575-2581. doi: 10.1017/S1368980015000737. Epub 2015 Mar 25

\section{How to cite this article?}

Meena S.K, Vivek Parasher. Anthropometric status of complicated severe acute malnutrition children at a tertiary care hospital in Southern Rajasthan, India. Int J Pediatr Res.2019;6(11): 555-560.doi:10.17511/ijpr.2019.i11.01 